\title{
La cumbia en Colombia: invención de una tradición
}

\section{The Cumbia in Colombia: an Invention of a Tradition}

\author{
por \\ Juan Sebastián Ochoa \\ Universidad de Antioquia, Colombia \\ juansochoa@gmail.com
}

\begin{abstract}
"Veo de ordinario que los hombres, en los hechos que se les presentan, prefieren ocuparse de buscar la razón que de buscar la verdad. [...] Pasan por encima de los hechos, mas examinan con cuidado las consecuencias. Suelen comenzar así: ¿Cómo ocurre esto? Mas, ¿̇ocurre?, habríamos de decir".
\end{abstract} (Montaigne, en Elster 2007:32).

La "cumbia", como cualquier otro concepto, es una construcción social. En este sentido, no se trata de una entidad ontológica que hay que descubrir, sino más bien de una creación humana que está en permanente transformación y negociación. Lejos de ser una música que ha sido descubierta de una vez y para siempre, es más bien una categoría mutante que se hace y rehace permanentemente a través de las prácticas y los discursos. Tomando esto en cuenta, el presente trabajo no dice qué es y qué no es la cumbia sino que muestra los distintos usos -a veces contradictorios- que se le ha dado al término, presenta los discursos que han construido un imaginario acerca de los orígenes y evolución de "la cumbia" en Colombia, y luego muestra sus correspondencias y falta de correspondencias con la evidencia empírica derivada del análisis histórico-musical. A partir de esto, indaga por las significaciones e implicaciones políticas que conllevan algunas de estas construcciones de sentido y concluye que el imaginario actual de la "cumbia" en Colombia corresponde a una ideología homogeneizadora y del mestizaje triétnico nacional que viene de la Constitución de 1886, la cual debe repensarse según la documentación empírica y a partir del reconocimiento de la multiculturalidad y diversidad que hace la Nueva Constitución de Colombia de 1991.

Palabras clave: cumbia, gaitas, flauta de millo, bandas de viento pelayeras, orquestas de baile, imaginario de nación en Colombia.

As any other concept, "cumbia" is a social construction. It is not an ontological entity that needs to be revealed, but rather a human creation in an ongoing process of transformation and negotiation. Far from being a type of music that has been discovered once and forever, it is a mutant category permanently made and remade through practices and discourses. In view of that, this paper does not attempt to say what is or what is not cumbia; it presents different and sometimes contradictory uses given to the term, exposes the discourses that have built an imagery on "the cumbia's" origins and evolution in Colombia, and reveals correspondences and incongruences with empirical evidence taken from historical and musical analysis. The paper examines the significations and 
political implications involved in the construction of sense and concludes indicating that the actual imagery of "cumbia" in Colombia responds to a homogenizing ideology rooted in three-ethnic national mestizaje that can be traced back to the 1886 National Constitution. "Cumbia" needs to be reconsidered according to an evaluation of empirical documentation and acknowledging the impact of diversity and multiculturalism recognized by the 1991 National Constitution.

Keywords: cumbia, Colombian gaita, flauta de millo, Pelayero wind bands, orchestras for dancing, Colombian nation's imagery.

\section{INTRODUCCIÓN}

La palabra “cumbia” es polisémica. Los significados más comunes son los siguientes: un baile y una práctica cultural, un conjunto de géneros (en plural), una categoría de mercado en la industria cultural, y un género (en singular) como matriz triétnica fundacional del resto de las músicas del Caribe colombiano. No obstante estas diferencias, tanto en Colombia como en otras partes de Latinoamérica se suele hablar de "la cumbia" como una entidad homogénea, sin reparar o tomar conciencia de los diferentes usos y significados que el término tiene en diferentes momentos y contextos. A lo largo de este texto se utilizará el término cumbia entre comillas siempre que se refiera a dicho uso homogéneo y ambiguo.

La "cumbia", como cualquier otro concepto, es una construcción social. En este sentido, no se trata de una entidad ontológica que hay que descubrir, sino más bien de una creación humana que está en permanente transformación y negociación. Lejos de ser una música que ha sido descubierta de una vez y para siempre, es más bien una categoría mutante que se hace y rehace permanentemente a través de las prácticas y los discursos. Tomando esto en cuenta, el propósito del presente trabajo no es decir qué es y qué no es la cumbia sino mostrar los distintos usos -a veces contradictorios- que se le ha dado al término, presentar los discursos que han construido un imaginario acerca de los orígenes y evolución de "la cumbia", para luego mostrar sus correspondencias y falta de correspondencias con la evidencia empírica derivada del análisis histórico-musical. A partir de esto, indagar por las significaciones e implicaciones políticas que conllevan algunas de estas construcciones de sentido.

Para pensar este trabajo en clave de memoria, vale la pena considerar lo señalado por Assman (2003: 23):

"La tarea del positivismo histórico consiste en separar los elementos históricos de los míticos en la memoria (...) Por el contrario, la tarea de la mnemohistoria consiste en analizar los elementos míticos de la tradición y descubrir su agenda oculta”.

La propuesta de Assman es trabajar en lo que él denomina la mnemohistoria, que consiste en la indagación acerca de la memoria colectiva por parte de la historia. La mnemohistoria no se pregunta cómo ocurrieron ciertos hechos, sino cómo son recordados y reconstruidos por una comunidad para la posteridad.

En tal sentido, este trabajo partirá desde el positivismo histórico para mostrar qué elementos históricos y qué elementos míticos tiene la memoria de la "cumbia". Este primer paso será necesario para mostrar el carácter mnemohistórico (y no 
histórico) de esta memoria ${ }^{1}$. Posteriormente, se hará el análisis desde la perspectiva mnemohistórica, en el cual se propondrá una interpretación de la agenda oculta que apoya esa particular memoria cumbiera².

\section{USOS DEL TÉRMINO "CUMBIA"}

De acuerdo a lo ya señalado, la palabra "cumbia" tiene varias denotaciones. Abordaremos cada una de ellas para tener una comprensión mínima, que nos permita luego cuestionar los usos homogeneizadores del término.

Como baile y práctica: este uso se refiere a la práctica cultural rural de los conjuntos musicales de "negros" e "indios" en el Caribe colombiano, en los que se agrupan personas a bailar alrededor de músicos con tambores y cantos (y en ocasiones algunos tipos de flautas). En esta acepción del término, se suelen intercambiar los términos "baile de cumbia", como el baile mismo en el sentido de danza y como la situación social en su conjunto, y “cumbiamba”. Este significado no remite entonces a un género o ritmo musical en particular sino a la práctica social de manera global. Se puede encontrar este uso principalmente en textos literarios o en crónicas de viajeros. Algunas referencias se encuentran en Bermúdez (2002/2003), Artel (1940) y Zapata (1962) ${ }^{3}$.

Como género $^{4}$ : se conoce como cumbia a algunos géneros específicos y bien delimitados musicalmente en la música de gaitas (Convers y Ochoa 2007; Ochoa 2013), en la música de flauta de millo (Valencia 2004), en la música de acordeón (Holand 2011) y en la música de orquesta de salón (Portaccio 1997). En la música de gaitas el género cumbia tiene un repertorio muy escaso. Apenas fue incorporado hace unos pocos años, quizás tomándolo como influencia de la música de flauta de millo ${ }^{5}$. En la música de millo, por su parte, sí es un género

1 El trabajo está enmarcado dentro de una perspectiva de indagación por la construcción de memoria. No obstante, es importante comenzar con una perspectiva histórico positivista, puesto que para poder hablar de los elementos míticos de la tradición, como lo sugiere Assman, es necesario primero mostrar su estatus mítico y no histórico. Assman aclara este punto en los siguientes términos: "En su calidad de rama de la historia, la mnemohistoria no puede vivir sin la historia. Es únicamente por medio de una continua reflexión histórica como se hace visible la obra de la memoria" (2003: 35). No se trata aquí de separar tajantemente la memoria de la historia, sino de enfatizar el carácter construido de ambas.

2 Según Álvaro Oviedo la memoria individual y la colectiva tienen dos componentes: los recuerdos reales y "ficticios", o las acciones vividas y las imágenes impuestas, o lo vivido y lo adquirido (Oviedo 2009: 80-81). En este sentido, la memoria de "la cumbia" que se indaga en este trabajo sería en parte una especie de recuerdo adquirido, no vivido, en cuanto a que se pregunta por las construcciones acerca del origen y evolución de "la cumbia" y no por las experiencias de la gente cuando oyó, bailó y cantó cumbias.

3 A modo de ejemplo, Delia Zapata comienza su artículo así: "En las costas tórridas de nuestros mares y a lo largo del Magdalena y otros ríos, se han esparcido propiciamente los africanos... y se baila la cumbia o cumbiamba con sin igual desenvoltura y frenesí rayano en el delirio...". (Zapata 1962: 188).

4 Bajo el término "género" me refiero aquí a una clasificación musical realizada por convención social, especialmente demarcada por características organológicas, rítmicas, melódicas y formales.

5 Los géneros más interpretados en la música de gaitas son la gaita (o gaita corrida), el porro, el merengue y la puya (Convers y Ochoa 2007; Ochoa 2013). 
de mucha importancia, con un repertorio amplio y de una trayectoria histórica que se pierde en el tiempo (Ochoa 2012 y 2013). En la música de acordeón, su aparición se le adjudica a Andrés Landero, conocido como "el rey de la cumbia" (Gil N. A. 2008; García 1994). La música de orquesta de salón se refiere a conjuntos del estilo de las big band norteamericanas y cubanas, como la de "Lucho" Bermúdez, "Pacho" Galán y Edmundo Arias (entre otras) surgidas en la década del cuarenta. Aquí se conoce como cumbia a un repertorio particular reconocido en canciones como "Yo me llamo cumbia", "Danza negra" y "Cumbia sabrosa". Estos cuatro géneros (cumbia de gaitas, cumbia de millo, cumbia de acordeón y cumbia de orquesta de salón) tienen similitudes en su aspecto rítmico, que se advierten en el tempo moderado, la métrica binaria con subdivisión binaria, y la acentuación permanente del contratiempo. No obstante, en lo que respecta a los aspectos melódicos, formales, tímbricos y armónicos son diferentes, por lo cual corresponden a cuatro géneros específicos y no a diferentes estilos dentro de un mismo género. Este punto se abordará en mayor detalle en el siguiente apartado.

Como un complejo de géneros con aire caribeño-colombiano en subdivisión binaria: este es quizás uno de los usos más comunes del término. Agrupa a muy diversas músicas del Caribe colombiano, tanto rurales tradicionales (música de gaitas, de flauta de millo, de acordeón, y también bailes cantaos) como urbanas modernizantes (orquestas de salón o conjuntos) que guarden una similitud rítmica como la señalada anteriormente. Así, el término cumbia aparece como una palabra abarcadora que une a las mismas cumbias mencionadas (de gaitas, de millo, de acordeón, de orquesta), con ritmos como el porro, la gaita, el bullerengue, la tambora, el chandé, el merecumbé, y en general toda clase de fusiones, innovaciones e hibridaciones que los músicos puedan inventar manteniendo esa misma estructura rítmica básica. Este es el sentido que se encuentra, a modo de ejemplo, en documentales como los de Rojas (2013) y Apuleyoy Forero (1967), en compilaciones de "cumbia" como la de Holland (2011), o en algunos textos de melómanos y coleccionistas (Jaramillo 1992; Peláez 1996). Igualmente, es el uso frecuente que se hace del término cumbia en otros países de Latinoamérica (Semán 2011; Fernández L’Hoeste 2013; Vila 2011).

Como categoría de mercado para músicas colombianas con sabor Caribe: este uso del término es un poco más amplio que el anterior, ya que no se requiere que la música comparta la similitud rítmica señalada, sino que basta con que tenga un cierto aire Caribe-colombiano. Funciona principalmente como estrategia de las disqueras para vender estas músicas bajo un solo término abarcador. Bajo esta acepción serían cumbieras agrupaciones como Los Corraleros de Majagual, la Billo’s Caracas Boys, Los Melódicos, Los Hispanos, entre otras ${ }^{6}$. Esto lo ha revisado con detalle Peter Wade para las décadas del cincuenta y sesenta (Wade

6 A los lectores no familiarizados con la producción musical de estas agrupaciones, se les sugiere ingresar a la web y escuchar al menos fragmentos de canciones de cada una de ellas. 
2002). En tal sentido, aparecerían también como cumbias géneros musicales en compás de 6/8 como el mapalé, el fandango de banda o el fandango de lengua.

Resumiendo, la cumbia aparece como una práctica social rural que implica música, baile y fiesta; como un complejo de géneros específicos dentro de los muchos que interpretan los conjuntos de gaitas, flauta de millo, acordeón y las orquestas de salón; como el conjunto de todas las músicas binarias de subdivisión binaria en tempos moderados con sonoridad del Caribe colombiano, y como categoría de mercado para vender todo lo que suene "costeño". Sin embargo, se ha señalado que estas diferencias no suelen ser reconocidas cuando se habla de "cumbia". Por ello el uso del término suele prestarse a ambigüedades y confusiones, y genera discursos problemáticos y usos políticos acerca de sus orígenes, evolución y significado simbólico. A fin de cuentas cuando se habla del origen y evolución de la "cumbia", debe explicitarse a qué sentido de cumbia se refiere. De otra manera el discurso que se elabore resultará ambivalente y difícil de corroborar desde una perspectiva histórica.

\section{CREACIÓN DE MEMORIA HISTÓRICA: ORÍGENES Y TRÁNSITOS}

Dice Gramsci que "No se puede separar la filosofía de la historia de la filosofía y la cultura de la historia de la cultura" (1983: 246). Parafraseándolo yo agregaría: no se puede separar la "cumbia" de la historia de la cumbia. Es decir, estudiar la "cumbia" implica necesariamente estudiar su construcción histórica, su emergencia, usos y continuas transformaciones. Habiendo presentado los diferentes significados del término, se abordarán a continuación los discursos más comunes sobre su origen y evolución, los cuales podrán ser interrogados tomando en cuenta las aclaraciones del apartado anterior.

En diversos textos de folcloristas, músicos y literatos aparece un uso homogeneizador del término "cumbia". La confusión de su uso, es decir, utilizarlo como género para explicar una categoría de mercado o para crear un mito fundacional, o utilizar la acepción de baile para tratar de explicar la difusión de un género específico, ha llevado a argumentaciones conflictivas. En última instancia, todos los usos del término se han combinado de una forma particular para construir un mito de origen y evolución de un supuesto género fundacional de las músicas de la región Caribe colombiana. Este mito, que se encuentra más o menos sedimentado hoy día, se puede resumir del siguiente modo:

1) la "cumbia" original sería la que interpretan los conjuntos de gaitas y los de flauta de millo, sobre lo cual se debate si esto implica un origen principalmente indígena $o$ afro.

2) Independientemente de si la cumbia original, primitiva o primigenia (según lo señalan algunos), tiene un origen más negro o más indígena, en última instancia se concreta en ella una mezcla armónica de las culturas indígenas, africanas y españolas, que supuestamente conforman la nación colombiana. 
3) La cumbia pasa luego a las bandas de viento sabaneras, conocidas como bandas pelayeras $^{7}$, en las que el clarinete asume las melodías de las flautas: gaitas o flautas de millo.

4) Finalmente, la cumbia pasa a las orquestas de salón, más estilizadas y modernizantes ${ }^{8}$.

A continuación, se considerarán algunos casos de la construcción de este imaginario del origen y evolución de la "cumbia"9. Algunas pistas se encuentran, a modo de ejemplo, en el poema La Cumbia, de Jorge Artel (1940):

\section{La cumbia (Jorge Artel)}

Hay un llanto de gaitas

diluido en la noche.

Y la noche, metida en ron costeño, bate sus alas frías

sobre la playa en penumbra, que estremece el rumor de los vientos porteños.

Amalgama de sombras y de luces de esperma, la cumbia frenética, la diabólica cumbia, pone a cabalgar su ritmo oscuro sobre las caderas ágiles de las sensuales hembras. Y la tierra, como una axila cálida de negra, su agrio vaho levanta, denso de temblor, bajo los pies furiosos que amasan golpes de tambor.

El humano anillo apretado es un carrusel de carne y hueso, confuso de gritos ebrios y sudor de marineros, de mujeres que saben a la tibia brea del puerto, al yodo fresco del mar $\mathrm{y}$ al aire de los astilleros.

Se mueve como una sierpe sonora de cascabeles, al compás de los chasquidos que las maracas alegres salpican sobre las horas desmelenadas de ruidos.

Es un dragón enroscado brotado de cien cabezas, que muerde su propia cola con sus fauces gigantescas.

¡Cumbia! -¡danza negra, danza de mi tierra!¡Toda una raza grita en esos gestos eléctricos, por la contorsionada pirueta de los muslos epilépticos!

Trota una añoranza de selvas y de hogueras encendidas,

7 Se trata de bandas conformadas principalmente por trompetas, clarinetes, bombardinos, bombo, redoblante y platillos. Se conocen como bandas "pelayeras" por ser el municipio de San Pelayo (Córdoba) uno de sus epicentros. En algunas regiones del país, en ocasiones de manera despectiva, se les conoce también como bandas papayeras.

8 Un texto que expone claramente estos imaginarios de la cumbia es "Tres razas... un ritmo: la cumbia" (Gil J. 1992).

9 Quizás la primera persona en ver esta construcción mítica fue el investigador Peter Wade quien habla de "el mito de origen de la cumbia" (2002). 
que trae de los tiempos muertos un coro de voces vivas.

Late un recuerdo aborigen, una africana aspereza, sobre el cuero curtido donde los tamborileros,

-sonámbulos dioses nuevos que repican alegríaaprendieron a hacer el trueno con sus manos nudosas, todopoderosas para la algarabía.

¡Cumbia! Mis abuelos bailaron la música sensual. Viejos vagabundos que eran negros, terror de pendencieros y de cumbiamberos en otras cumbias lejanas, a la orilla del mar...

Este poema es un buen ejemplo del imaginario de una cumbia de origen negro, el que se supone sensual, frenético y diabólico, interpretada con gaitas, maracas y tambores. Además, parece adscribirse a la primera acepción mencionada, en la cual no se trata de un ritmo en particular sino de una práctica social, un baile con velas, en la playa, alrededor del conjunto cumbiero.

Sobre la base de otra fuente, se puede considerar el imaginario de la "cumbia" que aparece en la canción "Yo me llamo cumbia", del compositor Mario Gareña10:

\section{Yo me llamo cumbia}

Yo me llamo cumbia, yo soy la reina por donde voy, no hay una cadera que se esté quieta donde yo estoy, mi piel es morena como los cueros de mi tambor, y mis hombros son un par de maracas que besa el sol. (bis)

Tengo en la garganta una fina flauta que Dios me dio, canuto de millo, olor de tabaco, aguardiente y ron, tomo mi mochila, enciendo la vela y repica el son, y enredo en la luna y en las estrellas toda mi voz. (bis)

Como soy la reina, me hace la corte un fino violín, me enamora un piano, me sigue un saxo y oigo un clarín, y toda la orquesta forma una fiesta en torno de mí, y yo soy la cumbia, la hembra coqueta y bailo feliz. (bis)

Yo nací en las bellas playas Caribes de mi país, soy barranquillera, cartagenera, yo soy de ahí, soy de Santa Marta, soy monteriana, pero eso sí, yo soy colombiana, ¡oh! tierra hermosa donde nací (bis).

10 Seudónimo de Jesús Arturo García Peña. Mario Gareña se fue a los 18 años a vivir a Bogotá, donde se estableció por cuarenta años. En la capital compuso esta canción. En entrevista en Wradio dijo que había compuesto "Yo me llamo cumbia" hace "casi cuarenta años". Eso implica que la canción es de mediados de los setenta (Gareña 2012). 
En esta canción, nuevamente aparece la "cumbia" como una expresión negra, un baile en la playa con velas, alrededor de músicos interpretando maracas y tambores. No obstante, a diferencia del poema de Artel, en lugar de gaitas la interpreta la flauta de millo y, además, se mencionan el piano, el saxo y un clarín (quizás refiriéndose al clarinete), con lo cual se introduce la idea del cambio de formato hacia las orquestas de baile.

Por otro lado, la discusión sobre si su origen es principalmente afro o indígena es de vieja data. Al respecto, señala Fabio Betancur (2012: 106):

"Pacho Galán, Antonio María Peñaloza, José Barros y Totó la Momposina, se inscriben en la tendencia que asume la cumbia desde su raíz indígena; y Lucho Bermúdez se inscribe en la otra tendencia que comparte con los hermanos Zapata Olivella y Jorge Artel que tanto hicieron con sus grupos de danzas y sus investigaciones a favor de las negritudes".

Lo importante de este punto es que a la cumbia se le ha atribuido un origen negro o un origen indígena, pero no un origen español. En tal sentido, se trata de una música "autóctona" que viene de un pasado inmemorial. Esto será central en la consideración ulterior de las construcciones simbólicas de sus orígenes ${ }^{11}$.

Por otra parte, la idea de una "cumbia" original interpretada por los conjuntos de gaitas y de flauta de millo se ha vuelto moneda corriente dentro de los discursos de folcloristas, melómanos y algunos académicos. A modo de ejemplo, se la encuentra reiteradamente en trabajos de folcloristas como Delia Zapata Olivella(1962), Javier Ocampo López (1970) y Abadía Morales (1995), en el documental 40 años de la música costeña (Apuleyo y Forero 1967), en algunos libros publicados por Discos Fuentes(Jaramillo 1992), en el trabajo compilatorio The Original Sound of Cumbia. The History of Colombian Cumbia E Porro as told by the Phonograph. 1948-79 (Holand 2011), así como en algunos textos académicos como los de Héctor Fernández L’Hoeste (2011), George List (1994), Leonardo D’amico (1993) y Néstor Lambuley (1988).

Considerando los formatos de gaitas y de flauta de millo como los representativos de la "cumbia" original, se ha asumido que la cumbia que ellos interpretan representa una conjunción armónica de las tres culturas que conforman la nación colombiana. En este relato, las gaitas, y en ocasiones la flauta de millo, representan el ancestro indígena por ser un instrumento prehispánico, así como por su sonido melancólico; los tambores representan la euforia negra, y el vestido y los textos son el aporte español. A manera de ejemplo, se puede indicar lo que señala Delia Zapata:

11 Sobre otras discusiones acerca del origen negro o indígena de la cumbia ver "Tambores o gaitas. La verdad sobre el origen de la cumbia”(Camargo 1992), en el que figuran extractos de dos artículos de periódico publicados en ElEspectador en 1971, con entrevistas a José Barros y a Efraín Mejía, director de la Cumbia Soledeña. Mientras que José Barros señala que la cumbia es indígena, Efraín Mejía afirma que es negra. Otro de los que defienden el origen indígena es Gerardo Pombo en su texto "Kumbia: legado cultural de los indígenas del Caribe colombiano" (Pombo 1965). 
"La comprobación del origen de la cumbia se liga a la integración del coctel americano y llega a las raíces de nuestro ancestro triétnico, cuyos tres ingredientes, mezclados ya en diferentes proporciones, forman la síntesis de la Nación colombiana".

"El tañido propio de los instrumentos que acompañan con su música la coreografía de la cumbia así lo demuestra: tambores de acento negro; flautas de gemido indígena; el vestido y el canto revelan el estilo hispánico" (Zapata 1962: 190).

"Un equipo o conjunto coreográfico en el que confluyen la rítmica euforia del negro, la cadenciosa melancolía del indio y el donaire del español”.

"Es como una síntesis musical de nuestra nacionalidad" (Zapata 1962: 200)12.

Esta idea de la trietnicidad del país, de la cual la "cumbia" es una música representativa, aparece de manera recurrente en los discursos sobre la "cumbia", según figura en los textos anteriormente citados ${ }^{13}$.

Junto con la noción de una "cumbia" original (o primitiva, como la llaman en ocasiones) interpretada en gaitas o flauta de millo y representativa de una nación triétnica, aparece la idea de dos tránsitos de la "cumbia”, o dos cambios de formato ya mencionados: un primer tránsito de los conjuntos de gaitas y flauta de millo a las bandas pelayeras, y un segundo tránsito de las bandas pelayeras a las orquestas de salón. Otra opción, según algunos, es un tránsito directo desde la música de gaitas y flauta de millo a las orquestas de salón. Uno de los que menciona esta posibilidad es el mismo Betancur cuando señala (2012: 109):

"Lucho Bermúdez afirmaba que las primeras orquestaciones del porro las hizo él, tomando de las gaitas y de los millos la base para los clarinetes y las flautas. Esto es bastante claro y de hecho hace parte de su estilo de orquestar. El retomar como referentes al conjunto de gaitas o a los cañamilleros es una expresión que tiene que ver con el antecedente indígena tanto del porro como de la cumbia y otros géneros".

Cronológicamente está claro que primero existieron los conjuntos de gaitas y de flauta de millo, al menos desde el siglo XIX, luego se conformaron las bandas pelayeras, a finales del siglo XIX y comienzos del XX, y por último aparecieron las orquestas de salón en Colombia en las décadas del veinte, treinta y cuarenta del siglo XX. No obstante, el afirmar que la cumbia primero se interpretó en gaitas y millo, de allí pasó a las bandas, y luego a las orquestas, no es suficiente. Es necesario demostrar la continuidad en términos musicales ya que un suceso anterior no necesariamente es causa de uno posterior. En tal sentido, siguiendo al metodólogo John Elster, "las explicaciones causales deben distinguirse de los enunciados causales verdaderos. Citar una causa no es suficiente: también es preciso señalar o al menos sugerir el mecanismo causal” (Elster 2007: 37). Esto implica que, para afirmar la idea evolucionista de la cumbia en este relato, sería necesario contestar por lo menos las siguientes preguntas: ¿la música de gaitas y la de flauta

12 El mismo título del texto de Delia Zapata (2012) es diciente: "La cumbia. Una síntesis musical de la nación colombiana".

13 Por ejemplo, el libro de List se titula: "Música y poesía en un pueblo colombiano. Una herencia tricultural" (List 1994). 
de millo son iguales, de tal manera que, como una sola cosa, puedan haber pasado a las bandas de viento?; ¿existe repertorio compartido entre las bandas de viento y los conjuntos de gaitas y de flauta de millo?; ¿'existe repertorio compartido entre las orquestas de baile y las bandas de viento sabaneras, y entre las orquestas y los conjuntos de gaitas y flauta de millo?; ¿los músicos de banda eran a la vez músicos de conjuntos de gaitas y/o flauta de millo?; ¿los compositores de orquesta de baile eran también intérpretes de gaitas o flauta de millo, o al menos conocían bien esas músicas como para poder haber interpretado las mismas músicas con distintos formatos?; ¿tienen las músicas de gaitas y flauta de millo, la de bandas de viento, y la de orquestas de baile, estructuras similares o diferentes?

Si bien este no es el espacio para hacer un análisis musicológico riguroso, presentaré rápidamente algunas consideraciones para tratar de responder estas preguntas. Mediante un breve análisis de músicas consideradas en distintos discursos como "cumbias", presentaré semejanzas y diferencias que permitan cuestionar los dos tránsitos mencionados, así como comprender más en detalle las diferencias entre los diversos usos del término que ya se han señalado.

El supuesto subyacente en los dos tránsitos a que se ha hecho referencia, es que el término "cumbia" se toma como un género musical en sí mismo, el cual simplemente cambió de formatos con el transcurso del tiempo. En tal sentido la pregunta sería: ¿la música de gaitas y la de flauta de millo son iguales, de tal manera que, como una sola cosa, puedan haber pasado a las bandas de viento y de allí a las orquestas de salón?14

Primero que todo, vale la pena aclarar que en la música de gaitas los géneros musicales más tradicionales y que mayor repertorio tienen son la gaita, el porro, el merengue y la puya. La cumbia, por el contrario, se incorporó hace apenas unas pocas décadas, y tiene muy poco repertorio. Quizás la cumbia de gaitas más conocida es "Fuego de cumbia" interpretada por los Gaiteros de San Jacinto (Convers y Ochoa 2007). En tal sentido, cuando se señala que una de las cumbias originales es la del conjunto de gaitas, esto no se refiere al género cumbia como tal, sino a los géneros binarios de subdivisión binaria en tempos moderados que interpretan estos conjuntos: la gaita y el porro. Se utilizaría entonces una acepción de cumbia no como un género específico sino como un conjunto de distintos géneros que tienen algunas similitudes.

En cuanto a la música interpretada por los conjuntos de flauta de millo, si bien los géneros corresponden al son corrido (también llamado jalaíto o porro), puya y cumbia, sí se considera a este último como uno de los más representativos de este formato. En este caso, se trata nuevamente de un género binario de subdivisión binaria, en tempo moderado y con acentuación del contratiempo. Sin embargo, las melodías interpretadas por las flautas de millo y por las gaitas tienen características muy diferentes; lo cual hace que no sean la misma música interpretada

14 Para toda esta sección se tomarán como fuentes los siguientes trabajos: Convers y Ochoa (2007), Ochoa $(2012 ; 2013 ; 2013)$ y Valencia $(1995 ; 2004)$. 
con diferentes instrumentos, sino que son músicas diferentes que comparten una similitud rítmica. No obstante, si se dice que son un mismo género por compartir algunas características rítmicas, el argumento no resulta del todo coherente, puesto que estas mismas similitudes rítmicas se advierten en otras músicas tradicionales del Caribe que no utilizan instrumentos de viento, como son algunos géneros de los llamados Bailes Cantaos (bullerengue, tambora-tambora, chandé, guacherna, son de negro, entre otros).

Sabemos entonces que las músicas de gaitas y la de flauta de millo no son la misma, ni que estos formatos interpretan solamente el género cumbias. Sobre esta base se la puede comparar con la música que ejecutan las bandas pelayeras. Éstas interpretan principalmente los géneros porro (tapao y palitiao) y fandango. No obstante, en su repertorio tradicional, al menos según lo exige el Festival del Porro de San Pelayo (Córdoba), no aparece la cumbia. Las bandas pelayeras están conformadas por bombo, redoblante y platillos, clarinetes, trompetas y bombardinos; en ocasiones participan además trombones y saxofones. El porro de banda es también un género binario de subdivisión binaria, en tempo moderado y con acentuación del contratiempo, lo cual lo asemeja a otros géneros musicales tradicionales del Caribe colombiano. En cuanto a la parte rítmica, en la sección llamada la bozá, en los porros de banda los platillos marcan los contratiempos al igual que lo hacen las maracas y el guache en la música de gaitas, la de flauta de millo y en algunos Bailes Cantaos; el bombo marca un patrón que también es común en los adornos de la tambora en la cumbia de millo y en el ritmo de gaita y el porro de gaita. Por su parte, el redoblante hace unos repiques muy particulares del género, pero que nada tienen que ver con la manera en que se interpreta el tambor alegre en la música de gaitas, en la de millo, en el bullerengue, y en la de tambora, entre otras. Es decir, el estilo de interpretación del redoblante de ninguna manera es una adaptación de los golpes del alegre, ni forma parte de un simple cambio de formato o tránsito musical de la "cumbia".

Pero más importante es considerar la parte melódica. Tanto las melodías de gaitas como las de millo tienen en su mayoría una configuración que las acerca a la armonía modal ${ }^{15}$, mientras que las melodías de los clarinetes, trompetas y bombardinos de las bandas pelayeras son casi siempre tonales y funcionales, de acuerdo a la progresión armónica de tónicas y dominantes. Se puede comparar, a manera de ejemplo, una melodía tradicional de gaitas y un porro tradicional de banda pelayera (ver ejemplos 1 y 2 ):

15 Modal en el sentido de los modos en la teoría del jazz o en las teorías de músicas populares modernas, y no en el sentido de música modal del Renacimiento europeo. 
Ej. 1 La Muerte ${ }^{16}$

Fragmento

\section{La Muerte}

Tradicional
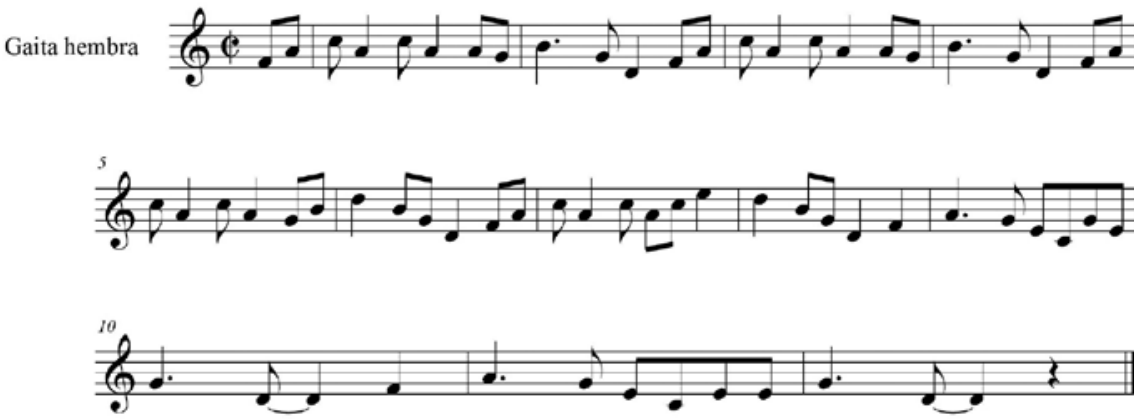

Ej. 2 El Binde ${ }^{17}$

Fragmento

\section{El Binde}

Tradicional
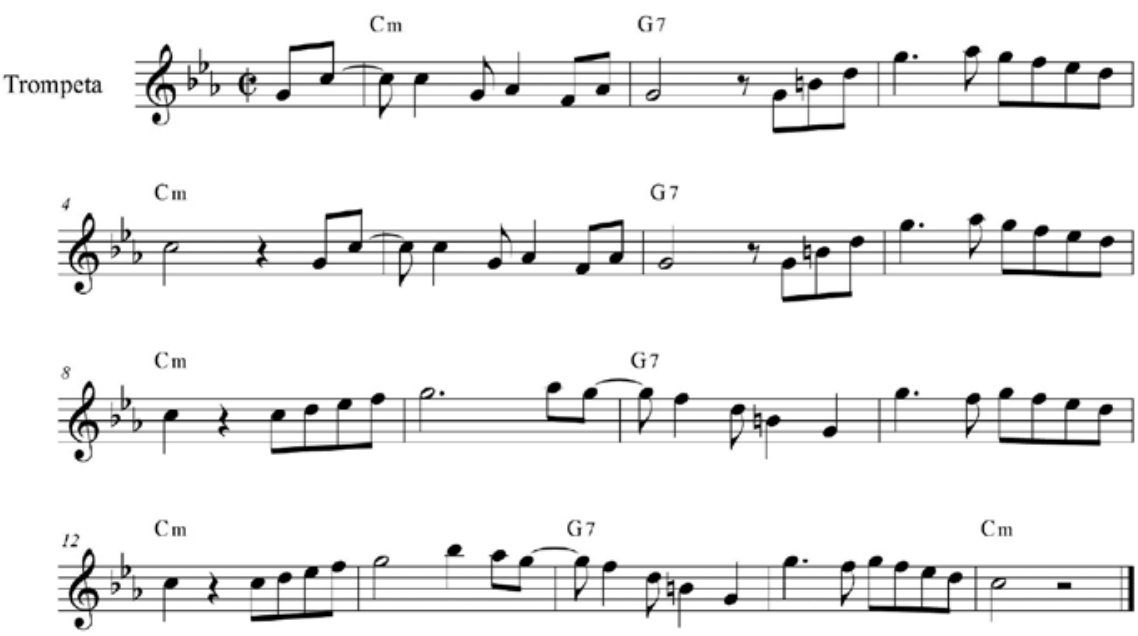

16 Las transcripciones son de mi propia autoría. Se pueden encontrar en web algunas versiones de ambos temas.

17 Este es uno de los porros de banda más tradicionales, que en algunas producciones aparece bajo la autoría de Alejandro Ramírez Ayazo. No obstante, su autoría se la adjudica también el trompetista Primo Paternina. Ambos actuaban en la misma banda -Banda Ribana de San Pelayo- en el momento en que se comenzó a escuchar este porro, por lo que no está clara su autoría. Incluso, podría ser de autoría colectiva, o podría venir de una tradición oral anterior. Para una discusión sobre la autoría de este y otros porros, ver http://porro-pelayero.blogspot.com.co/. 
De esta manera, la única característica compartida entre algunas músicas de gaitas y de flauta de millo con los porros de bandaes que interpretan géneros binarios de subdivisión binaria, en tempos moderados y con acentuación del contratiempo. Esta similitud no resulta suficiente para justificar un simple cambio de formato musical sino que, más bien, corresponden a músicas diferentes que provienen de una misma macro región (el Caribe colombiano) y comparten cierto sentido rítmico, cierto aire, cierto sabor ${ }^{18}$.

Por otro lado, un factor que enfatiza la falta de correspondencia directa entre las músicas de gaitas y millo con la música de bandas pelayeras, es que la mayoría de los músicos de bandas no interpretan música de gaitas ni música de millo. Además, los repertorios de estas tradiciones no son compartidos, ni se suelen encontrar melodías ni letras compartidas entre ellos. Un último elemento que permite cuestionar este supuesto tránsito de la cumbia guarda relación con las regiones específicas donde más se practica cada formato. La música de flauta de millo se interpreta principalmente en el departamento del Atlántico, con énfasis en el área metropolitana de Barranquilla; la música de gaitas se interpreta en la región de los Montes de María (que abarca zonas de los departamentos de Córdoba, Sucre y Bolívar), mientras que la música de bandas se ejecuta principalmente en las sabanas de los departamentos de Córdoba y Sucre. Es decir, estas tres músicas no comparten un mismo espacio geográfico, lo cual hace aún más problemática la creencia en un simple cambio de formato producido por un mismo tipo de música.

Todo lo que se ha esbozado de manera muy rápida, lleva a cuestionar ese primer tránsito que se ha señalado. Por lo tanto, no es dable afirmar que la música de gaitas y la de flauta de millo hayan pasado a la música de bandas pelayeras, como lo sugiere el discurso canónico de la "cumbia".

Consideremos ahora el segundo tránsito, de acuerdo al cual la "cumbia" pasa de las bandas pelayeras a las orquestas de salón. Muchos de los compositores y músicos de orquestas de salón sí tuvieron experiencia y aprendizaje en las bandas pelayeras. Músicos como "Lucho” Bermúdez, Clímaco Sarmiento y "Pacho” Galán, todos ellos instrumentistas de viento, pasaron en algún momento por bandas pelayeras (Portaccio 1997; Stevenson 2006; Santana y Bassi 2012). Esto permite pensar que era fácil para ellos adaptar música de bandas a orquestas de salón. Incluso, el formato lo permitía: las orquestas de salón, en gran medida, funcionaban como bandas pelayeras complementadas con instrumentos como el contrabajo y el piano.

Por otra parte, las similitudes entre la música de bandas y una parte del repertorio de las orquestas de salón resultan fáciles de descubrir. Una obra como

18 El músico e investigador Arlington Pardo ha señalado lo mismo en un texto reciente (2014: 151): "Pero hay algo en lo que insisten los investigadores y es en decir que los músicos de pitos y tambores tocaban porro (...), pero no corresponde al formato y forma del porro actual ejecutado por las bandas surgidas a finales de 1800 y principios de 1900 en la costa Caribe colombiana, debido a que las estructuras melódicas, armónicas y el concepto de arreglos e instrumentación no concuerda con las prácticas musicales de los formatos de pitos y tambores". 
"Fiesta de negritos", de "Lucho" Bermúdez, es claramente un porro palitiao interpretado por una orquesta de salón, incluyendo la contradanza inicial típica de estos porros. Lo mismo se puede decir de una composición como "Tolú", también de Bermúdez. En general, el uso armónico de sucesión de tónicas y dominantes, las melodías triádicas y de carácter responsorial, son típicas tanto de las bandas pelayeras como de una buena parte del repertorio de cumbias, porros y gaitas de las orquestas de salón ${ }^{19}$. Sin embargo, este tránsito de las bandas a las orquestas no sería un tránsito de la cumbia como género específico, sino de los porros de banda que, al llevarse a las orquestas, con pequeñas variaciones en la sección rítmica y en el ritmo armónico se conocieron como cumbias, gaitas y porros. En tal sentido, el tránsito no sería del género cumbia en específico, sino de una acepción de cumbia en el sentido de un grupo de géneros que comparten las similitudes rítmicas mencionadas.

Si bien este tránsito de banda pelayera a orquesta de salón resulta claro, con la salvedad mencionada, éste no implica que la música de gaitas y de flauta de millo en su conjunto pasaron también a las orquestas de salón. Según se señaló anteriormente, las características melódicas y armónicas de la música de gaitas y de millo son muy diferentes a las de las bandas pelayeras, y por ende son distintas a las de las orquestas de salón. Según se puede apreciar en las trayectorias de músicos como "Lucho" Bermúdez y "Pacho" Galán, ellos conocían de primera mano la música de bandas. No obstante, ellos no fueron intérpretes de gaitas ni de flautas de millo, lo cual puede explicar, al menos en parte, por qué no se encuentran mayores relaciones entre estas músicas y las de las orquestas de salón. Quizás, la única semejanza sea el uso del maracón en estas orquestas, y en ocasiones también el uso del tom de piso en la batería marcando un patrón similar al de la tambora en la cumbia de millo ${ }^{20}$. Sin embargo, las orquestas de salón no interpretan repertorio de gaitas ni de flauta de millo, y las construcciones melódicas tienen una mayor similitud con las bandas pelayeras.

Un dato más que permite cuestionar ese supuesto tránsito de la música de millo y de gaitas a las orquestas de salón, es que fue en 1991 que se realizó la primera grabación de una flauta de millo en un formato de orquesta para la canción "Que no muera la cumbia", interpretada por el cantante Checo Acosta (Ochoa 2013). En el caso de la gaita no conozco datos de grabaciones de orquestas de baile que la incluyan. No obstante, un referente similar puede ser su aparición en la agrupación de Carlos Vives y La Provincia en el disco Clásicos de la Provincia (1993). Sin embargo, ni "Lucho" Bermúdez, ni "Pacho" Galán, ni Edmundo Arias, ni Clímaco Sarmiento, ni ningún otro compositor y director de la época dorada

19 Esto, sin olvidar que las orquestas de salón también interpretaban muchos otros géneros que no provenían del Caribe colombiano, como tangos, boleros, swing jazz, pasillos y bambucos, entre otros.

20 Vale la pena aclarar que este mismo patrón de la tambora en las cumbias interpretadas con el conjunto de flauta de millo se utilizó luego en la música de gaitas. Hasta mediados del siglo XX, el formato de la música de gaitas no incluía tambora. Se le adjudica a Catalino Parra, al ingresar al grupo Los Gaiteros de San Jacinto a mediados de los cincuenta, la inclusión de este instrumento que interpreta el mismo patrón de la cumbia de los conjuntos de millo. Con el pasar del tiempo, la tambora se ha afianzado en los conjuntos gaiteros, a tal punto que se exige su presencia para participar en los festivales. 
de las orquestas de salón incluyeron gaitas o flautas de millo, ni tambores alegre, en sus instrumentaciones ${ }^{21}$.

Lo que resulta de esta comparación rápida entre las músicas de gaitas y flauta de millo, con la música de bandas y de orquesta de salón es que, si bien el primer tránsito mencionado no se sostiene con una mirada histórica y musicológica, el segundo tránsito sí resulta lógico, al menos en una parte de su repertorio. No obstante, el supuesto paso desde la cumbia de gaitas a la cumbia de orquesta, si bien tiene un cierto sentido cronológico, no se apoya en ninguna correspondencia que permita sustentarlo. Por el contrario, la evidencia lo contradice, lo cuestiona, y nos conduce a la siguiente pregunta: ¿cómo, por qué y para qué se ha construido esta memoria histórica de la "cumbia”?, ¿qué agendas ocultas puede tener, o qué significados sociales implica?

\section{SIGNIFICACIONES Y USOS POLITICOS DE LA MEMORIA CUMBIERA}

De acuerdo a lo señalado en el apartado anterior, la memoria de la cumbia se ha construido sin la ayuda de una investigación histórica y musical rigurosa, lo cual ha creado un imaginario no sometido a comprobación empírica ${ }^{22}$. Siguiendo a Koselleck: "se puede situar un acontecimiento histórico, pero no discrecional o arbitrariamente pues la comprobación de las fuentes excluye lo que no se puede decir. Pero no prescribe lo que se puede decir"(1993: 147-148). En este sentido, la ausencia de fuentes en la narración sobre los orígenes y tránsitos de la "cumbia" es lo que ha ampliado el espectro de "lo que se puede decir" acerca de ella, ha permitido enormes libertades para construir un relato que tiene más de ideológico que de histórico, sin desconocer que las construcciones históricas también están permeadas por lo ideológico. Como resultado, no se cuenta con una historia de la "cumbia", sino con una memoria.

Sin embargo, como bien lo señalan los estudios sociales y culturales sobre la memoria, la no correspondencia histórica de una construcción de memoria no la invalida sino que, más bien, plantea la pregunta acerca de qué sentidos y agendas

21 Otro aspecto que permite cuestionar este tránsito de la música de gaitas y de flauta de millo a las orquestas de salón tiene que ver con el ingreso de estas músicas a la industria discográfica. Con el surgimiento de las grabaciones fonográficas en el país las orquestas de salón comenzaron sus registros en las décadas del treinta y cuarenta, primero en Barranquilla y Cartagena, y desde finales de los cincuenta principalmente en Medellín. La primera grabación de un grupo de gaitas es de los Gaiteros de San Jacinto en la década del setenta, y las primeras grabaciones de flauta de millo son de La Cumbia Soledeña. con un sencillo de $78 \mathrm{rpm}$ de finales de los cincuenta, y un primer larga duración en 1963 bajo el título "Pa' gozá el Carnaval" (Ochoa 2013). A juzgar por la difusión fonográfica y radial, es más probable que los grupos de gaitas y flautas de millo se hubieran influenciado por la sonoridad de las orquestas de salón, que las orquestas de salón recibieran influencias de las gaitas y las flautas de millo.

22 En este sentido, se trata de una memoria creada principalmente desde los discursos de los folcloristas, los cuales, en su mayoría, han estado más cercanos a la memoria popular que al discurso académico. No se podría hablar entonces de una memoria que va de arriba hacia abajo, de los discursos "oficiales" a las memorias populares, sino que está en el intersticio entre lo popular y lo oficial. Se trata de un saber más cercano al sentido común que al discurso académico, aunque en ocasiones haya tenido pretensión de validez científica. 
ocultas hay detrás de esa particular construcción de memoria. En pocas palabras ¿qué significados sociales y usos políticos puede tener esta construcción mítica del origen y evolución de la "cumbia”, ya sea para una nación, para una región o para una comunidad?

Por otro lado, las memorias cobran sentido y se producen dentro de marcos sociales particulares, esto es, contextos sociales y configuraciones epistemológicas específicas de las sociedades que funcionan como condiciones de posibilidad de esas particulares construcciones de memoria (Candau 2002). De esta manera, para intentar comprender esa memoria cumbiera es necesario preguntarse por esos marcos sociales que la posibilitan y que en cierta medida también la producen. Al respecto, escribe Kosseleck: "No se puede narrar un acontecimiento sin representar alguna estructura, sin describir algún proceso, sin que haya que aplicar conceptos históricos que permiten «concebir» el pasado" (1993: 150).

Desde esta perspectiva teórica, se puede señalar que esta memoria de la "cumbia" que se ha presentado, responde a la construcción de un ideal moderno de nación el cual buscaba crear el imaginario de una sociedad homogénea. En el caso colombiano particular, la búsqueda por esa comunidad imaginada de nación, en el sentido de Anderson (1993), señalada con claridad en la constitución de 1886, planteaba el anhelo de una comunidad que compartía "una sola lengua, una solaraza, un solo Dios" (Charry 2011). Era un anhelo por una Colombia creada a partir del mestizaje entre las culturas (supuestamente homogéneas) blancaeuropea, indígena-americana y negra-africana, en la que se hablaba el castellano y se seguía la religión católica.

Para construir esta comunidad homogénea imaginada, se hacía necesario entonces encontrar elementos culturales comunes y con una larga historia, que permitieran crear una continuidad y un anclaje con el pasado. Es dentro de este marco social que la mnemohistoria de la cumbia adquiere sentido, según se indica a continuación.

Para crear ese artefacto cultural representativo de la nación es importante contar con unos elementos simbólicos que nos anclen al pasado inmemorial, por lo cual deben preferiblemente ser elementos de las culturas no hegemónicas, es decir, elementos asociados a lo indígena o a lo africano. Es ahí donde cobra relevancia el apelar a una "cumbia" original interpretada en los conjuntos de gaitas y flauta de millo: ambos instrumentos permiten simbolizar un carácter "ancestral", un pasado inmemorial y "autóctono", muy "nuestro”, "propio”. Quizás por esto, la tradición de la cumbia de acordeón no suele formar parte de las memorias de los orígenes de la "cumbia", puesto que el acordeón, al ser un instrumento de origen europeo y haber llegado a Colombia a finales del siglo XIX, no es posible concebirlo de la misma forma ancestral y autóctona que sí lo permiten las gaitas y las flautas de millo.

Por otro lado, la memoria de una "cumbia" triétnica, en la que se ensamblan de manera armónica las raíces africanas, indígenas y europeas, según lo indicaba Delia Zapata, remite de forma clara a la idea de una nación mestiza en la que las diferentes influencias se han mezclado de tal manera que ya no es posible separarlas: como nación homogénea, todos tenemos la misma genealogía. Y mejor aún, 
este mestizaje, si bien surgió de situaciones complejas, desiguales e incluso inhumanas, como lo fue la trata esclavista y la reducción de los indígenas, el resultado ahora es armónico y feliz. Como lo señala explicítamente Delia, "es la síntesis de la nación colombiana" (Zapata 1962: 190) ${ }^{23}$.

Además, los dos tránsitos mencionados, desde la música de gaitas y flauta de millo de un pasado inmemorial hasta las orquestas de salón del siglo XX, representan una mirada evolucionista de la "cumbia", y por ende de la "nación colombiana", una mirada evolucionista que lleva a Colombia de lo rural-tradicional a lo urbano-moderno. Esto es el relato de una nación colombiana que parte de orígenes ancestrales autóctonos y evoluciona hasta llegar a un estadio de modernidad, con una sociedad homogénea que, mirando hacia el pasado, avanza hacia el futuro, como un crisol alegre en el que convivimos y nos sentimos representados todos los colombianos.

Por último, según lo señala Ana María Tamayo (2013), a través del baile de la cumbia también se construye una imagen de colombianidad, puesto que se crea una normalización del baile en el cual las parejas no se tocan, la mujer es altiva y orgullosa, recatada y bella, y usa una pollera larga que le cubre el cuerpo. Por ser de tempo moderado y con un baile de no contacto, con las mujeres vestidas completamente, y en una actitud orgullosa y altiva, la cumbia como música refleja un proceso de blanqueamiento, que pasa de la efervescencia erótica de los bailes rápidos asociados a lo negro, y por ende a lo salvaje, de músicas como el fandango, el mapalé o la puya, para llegar a una música tranquila, mesurada, controlada, altiva y elegante, perfecta para la simbolización de una Colombia civilizada ${ }^{24}$. Mientras las mujeres en la cumbia van vestidas con falda hasta el piso y blusa, en otras músicas más racializadas hacia lo negro, como el mapalé, las mujeres van menos vestidas, bailan con movimientos más frenéticos y con una mayor exaltación del cuerpo, lo que no los hace idóneos para ser reconocidos como símbolos del alma nacional ${ }^{25}$. Visto así en conjunto, la memoria de la "cumbia" constituye un atractivo y poderoso relato de un proyecto exitoso de construcción de una nación.

Sin embargo, como se ha tratado de demostrar a lo largo de este texto, se trata de una memoria y no de una historia de la cumbia como correlato nacional. En este sentido, se trata de una tradición inventada y, como dicen Hobsbawm y Ranger: "todas las tradiciones inventadas, hasta donde les es posible, usan la historia como legitimadora de la acción y cimiento de la cohesión del grupo” (1983: 19) 26. La

23 Esta misma crítica la presenta Tamayo (2013).

24 De hecho, según Tamayo, el adjetivo más repetido para describir el baile de la cumbia es "hierático" (2013: 80).

25 Federico Ochoa afirma que este blanqueamiento del baile de la cumbia, en el sentido de más recatado y menos corpóreo, ha servido para que las elites barranquilleras envíen a sus hijas a participar como candidatas a reinas del Carnaval (Ochoa 2013).

26 Así como las tradiciones son inventadas, el concepto de nación también lo es, al ser construidos de forma narrativa (Bhabha 2010: 11). Al hablar de la nación como narración, se enfatiza el carácter construido de esta noción: la nación no es algo a lo cual la civilización debía llegar en algún momento, mirada teleológica, sino que es una construcción cultural contingente, y por lo tanto no es necesaria. Esas narraciones se dan de múltiples formas, una de las cuales la constituyen los discursos de los 
memoria de la cumbia funciona entonces como un correlato de la historia de la nación, y sirve como legitimadora de ese imaginario de nación heredado de la Constitución de 1886. No obstante, cabe preguntarse: ¿cómo encaja esta memoria dentro del discurso de nación propuesto por la Constitución de 1991?

La llamada Nueva Constitución de Colombia concibe al país como una nación pluriétnica y multicultural. Esto implica que, lejos de buscarse un mestizaje armónico, una homogeneización total de los colombianos, se reconoce y respeta la diversidad cultural y étnica del país, junto con proteger el derecho a la no asimilación de las comunidades indígenas y afros. Bajo este nuevo paradigma de nación, la memoria de la cumbia se revela en su carácter ideológico y se hace menos atractiva y más fácilmente cuestionable. No obstante, esa memoria cumbiera sigue siendo utilizada y reforzada por músicos de trayectorias más recientes, como por ejemplo Carlos Vives. En numerosas entrevistas él recalca que la cumbia es la madre de nuestras músicas, la que une a los colombianos y María Mulata reconocido principalmente en su disco Los vestidos de la cumbia, en el cual plantea la idea de la cumbia como un sentir musical que une a las diferentes músicas tradicionales colombianas ${ }^{27}$. Quizás, y lo enuncio a manera de hipótesis, el que músicos populares colombianos apelen en estos momentos a estas mismas memorias de la "cumbia", puede tener que ver con un intento de posicionamiento a nivel latinoamericano ya que, en los últimos años, distintas manifestaciones derivadas de la cumbia colombiana se han transformado en músicas importantes en países como Argentina, México, Chile y Perú, entre otros. Con un incremento del interés por las cumbias en el mercado latinoamericano, y al ser reconocido que la cumbia surgió en Colombia, puede ser lógico que los músicos colombianos quieran apelar a un esencialismo de la "cumbia" para posicionarse en mercados fuera del local.

\section{CONCLUSIÓN}

Como señala Benedict Anderson: "La magia del nacionalismo es la conversión del azar en destino" (1993: 29). La memoria de la "cumbia" ha cumplido su tarea de construir un relato acerca de los orígenes y desarrollo de la "cumbia" desde una perspectiva evolucionista, casi teleológica, convirtiendo ese azar musical de la región Caribe colombiana en un feliz destino de la nación. Anderson indica que la novela y el periódico "proveyeron los medios técnicos necesarios para la 'representación' de la clase de comunidad imaginada que es la nación” (1993: 47). No obstante, en las sociedades latinoamericanas es tal vez más preciso pensar que una de esas correas de transmisión de las memorias de nación

\footnotetext{
folcloristas que, como su nombre lo indica, estudian las manifestaciones de "el pueblo", un concepto también contingente y en permanente construcción.

27 También es interesante que en el disco "El Rock de mi Pueblo" Vives insista en que "la cumbia es el rock de mi pueblo", como haciendo el paralelo que si el rock representa a Estados Unidos, la cumbia representa a Colombia. Un análisis detallado de este uso simbólico que hace Vives de la cumbia lo presento junto con otros colegas en Sevilla et al. 2014.
} 
y de la construcción de comunidades imaginadas la constituyeron los medios masivos de comunicación como la radio y la industria fonográfica. Con ellos, la música se convirtió en un vehículo privilegiado para formar imaginarios y memorias colectivas. Es por ello que los discursos acerca de la cumbia como una manifestación donde se integra la nación, tienen tanto poder político y se pueden sedimentar con facilidad.

La idea de "la cumbia" como algo homogéneo acerca de lo cual se puede hablar en singular, nos mantiene en la noción de mestizaje, e impide comprendernos como diversos y múltiples. Más que apelar a un grupo en particular, mantiene las lógicas modernas del Estado Nación en cuanto a un espacio, tiempo y comunidad homogéneos, noción que explotó con la Constitución del 91. Sin duda, estamos en mora de historizar la cumbia -o mejor, las cumbias- y repensarla según las necesidades de los nuevos tiempos.

\section{BIBLIOGRAFÍA}

Abadía, Guillermo

1995 ABC del folklore colombiano. Bogotá: Panamericana.

ANDERSON, BENEDict

1993 Comunidades imaginadas: reflexiones sobre el origen y la difusión del nacionalismo. México: Fondo de Cultura Económica.

Apuleyo, Plinio y Ester Forero

1967 Cuarenta años de música costeña. mixcloud. [En línea]. http://www.mixcloud.com/ ebiruojaba/40-anos-de-musica-costena-la-historia-de-la-cumbia-colombiana/. Consulta el 20 de septiembre de 2016.

ARTEL, JoRge

1940 Tambores en la noche. Cartagena: Bolívar.

Assman, Jan

2003 Moisés el egipcio. Madrid: Anaya.

BERMúdez, EgBerto

2002/2003 "Poro-Sande-Bunde: vestigios de un complejo ritual de África occidental en la música de Colombia”, Ensayos. Historia y Teoría del Arte, VII/7, pp. 5-57.

Betancur, Fabio

2012 "Bajo el cielo azul un viento verde: Lucho Bermúdez en Medellín”, en Sergio Santana y Rafael Bassi (editores). Lucho Bermúdez: cumbias, porros y viajes. Medellín: Ediciones Santo Bassilón, pp. 91-112.

BНАвна, Номі

2010 "Introducción: narrando la nación", en Homi Bhabha. Nación y narración: entre la ilusión de una identidad y las diferencias culturales. Buenos Aires: Siglo Veintiuno Editores, pp. 11-19.

Camargo, Jaime Eduardo

1992 "Tambores o gaitas. La verdad sobre el origen de la cumbia”, en Luis Felipe Jaramillo (editor). Música tropical y salsa en Colombia. Medellín: Ediciones Fuentes, pp. 35-48. 
CANDAU, Joel

2002 Antropología de la memoria. Buenos Aires: Nueva Visión.

Charry, Carlos Andrés

2011 "Los intelectuales colombianos y el dilema de la construcción de la identidad nacional (1850-1930)", European Review of Latin American and Caribbean Studies, $\mathrm{N}^{\circ} 90$, pp. 55-70.

Convers, Leonor y Juan Sebastián Ochoa

2007 Gaiteros y tamboleros: material para abordar el estudio de la música de gaitas de San Jacinto, Bolívar (Colombia). Bogotá: Editorial Javeriana.

D'AMICO, LEONARDO

1993 Moduli ritmici e poliritmici della musica afrocolombiana. Bologna: "Universita' degli studi di Bologna. Tesi di Laurea. Discipline delle Arti, Musica e Spettacolo. Materia di tesi: Etnomusicologia”.

ELSTER, JOHN

2007 La explicación del comportamiento social. Barcelona: Gedisa.

FERnández L'Hoeste, Héctor

2011 "De música y colombianidades: en torno a una historia de la cumbia, la parrandera”, en Pablo Semán y Pablo Vila (editores).Cumbia: nación, etnia y género en Latinoamérica. Buenos Aires: Gorla, pp. 139-166.

Fernández L'Hoeste, Héctor y Pablo Vila

2013 Cumbia!: Scenes of a Migrant Latin American Music Genre. Durham: Duke University Press.

García, Jorge y Alberto Salcedo

1994 Diez juglares en su patio. Bogotá: Ecoe.

Gareña, Mario

25 de septiembre de 2012 Wradio. Recuperado en septiembre de 2013, de http://www. wradio.com.co/escucha/archivo_de_audio/el-maestro-mario-garena-autor-de-yo-me-llamo-cumbia-hablo-con-la-w/20120925/oir/1767611.aspx

GIL, JAVIER

1992 "Tres razas... un ritmo: la cumbia”, en Luis Felipe Jaramillo (editor). Música tropical y salsa en Colombia. Medellín: Ediciones Fuentes, pp. 13-34.

Gil, Numas Armando

2008 Mochuelos cantores de los Montes de María III: Andrés Landeros el clarín de la montaña. Bogotá: Kimpres.

Gramsci, Antonio

1983 Cuadernos de la cárcel. México: Era.

Hobsbawm, Eric y Terence Ranger (editores)

1983 La invención de la tradición.Cambridge: Cambridge University Press.

Holand, William (COMPILADOR)

2011 The Original Sound of Cumbia. The History of Colombian Cumbia as told by the Phonograph. 1948-79. CD: W. Holand.

Jaramillo, Luis Felipe

1992 Música tropical y salsa en Colombia. Medellín: Ediciones Fuentes. 


\section{Koselleck, ReINHART}

1993 Futuro pasado. Para una semántica de los tiempos históricos. Barcelona: Paidós.

\section{LAMBUley, NÉSTOR}

1988 "La cumbia: un gran sistema caribe-colombiano", en A contratiempo. Revista de Música en la Cultura. Bogotá: Biblioteca Nacional. Obtenido de http://www. territoriosonoro.org/CDM/acontratiempo/files/ediciones/revista-3/pdf/ Rev3_15_La\%20cumbia.pdf. Última consulta el 20 de septiembre de 2016.

List, GEORGE

1994 Música y poesía en un pueblo colombiano. Una herencia tricultural. Bogotá: Colegio Máximo de las Academias Colombianas - Patronato Colombiano de Artes y Ciencias.

OCAMPO, JaVIER

1970 El folklore y su manifestación en las supervivencias musicales en Colombia. Tunja: Universidad Pedagógica y Tecnológica de Colombia.

OCHOA, FEDERICO

2012 "Las investigaciones sobre la caña de millo o pito atravesao",Cuadernos de Música, Artes Visuales y Artes Escénicas, volumen 7, № 2, pp. 159-178.

2013 El libro de las gaitas largas. Tradición de los Montes de María. Bogotá: Editorial Javeriana.

2014 La cumbia en el Carnaval de Barranquilla. Medellín: Tesis para optar al grado de Maestría en Antropología, Universidad de Antioquia. Darío Blanco (Asesor).

Oviedo, Álvaro

2009 "Apuntes para el debate memoria colectiva y movimientos sociales", en Absalón Jiménez y Francisco Guerra (compiladores). Las luchas por la memoria. Bogotá: Ipazud, pp. 77-92.

Pardo, Arlington

2014 Elementos constitutivos del porro pelayero, en Antecedentes y origen del porro pelayero, de Jesús Manuel Paternina. Sin ciudad: SS Encuadernación y Empastes, pp. 151-160.

Peláez, Ofelia y Luis Felipe Jaramillo

1996 Colombia musical: una historia... una empresa. Medellín: Discos Fuentes.

Pombo, Gerardo

1965 Kumbia, legado cultural de los indígenas del caribe colombiano. Barranquilla: Antillas.

Portaccio, José

1997 Carmen tierra mía. Lucho Bermúdez. Bogotá: Disformas Triviño (editor).

Rojas, Juan SEbastián

2013 "Cumbia: The Construction of a Musical Genre in the Mid-twentieth Century", en Archives of Tradicional Music. Recuperado en junio de 2013, de http://www. indiana.edu/ libarchm/index.php/outreach/podcasts/cumbia-the-constructionof-a-musical-genre-in-the-mid-twentieth-century.html

Santana, Sergio y Rafael Bassi (editores)

2012 Lucho Bermúdez. Cumbias, porros y viajes. Medellín: Ediciones Santo Bassilón.

Semán, Pablo y Pablo Vila (compiladores)

2011 Cumbia: nación, etnia y género en Latinoamérica. Buenos Aires: Gorla. 
Sevilla, Manuel, et al.

2014 Travesías por La Tierra del Olvido: modernidad y colombianidad en la obra de Carlos Vives y La Provincia. Bogotá: Editorial Javeriana.

Stevenson, Adlai

2006 Pacho Galán. El rey del merecumbé. Barranquilla: La Iguana Ciega.

Tamayo, Ana María

2013 En Colombia se baila así: Intersectional Bodies, Race, Gender, and Nation Building in the Barranquilla Carnival. Tesis para optar al grado de Doctora en Estudios Críticos de la Danza. Riverside: Universidad de California. Marta Savigliano (profesora guía).

Torres, Alfonso

2009 "Memorias de luchas y organizaciones populares en Bogotá", en Absalón Jiménez y Francisco Guerra (compiladores). Las luchas por la memoria. Bogotá: Ipazud, pp. 63-76.

VALENCIA, Victoriano

1995 El porro palitiao: análisis del repertorio tradicional. Tesis de pregrado para optar al título de Pedagogo Musical. Bogotá: Universidad Pedagógica de Colombia. Director: Carlos Miñana Blasco.

2004 Pitos y tambores. Cartilla de iniciación musical. Bogotá: Ministerio de Cultura.

Vila, Pablo y Pablo Semán

2011 Troubling Gender: Youth and Cumbia in Argentina's Music Scene. Philadelphia: Temple University Press.

WAde, Peter

2002 Música, raza y nación. Música tropical en Colombia Nacional de Planeación-Programa Plan Caribe. Traducción de Adolfo González Henríquez. Bogotá: Vicepresidencia de la República de Colombia-Departamento.

Zapata, Delia

1962 "La cumbia: síntesis musical de la nación colombiana", Revista colombiana de folklor, Vol. 3, $\mathrm{N}^{\circ}$ 7, pp. 187-204. 